\title{
Producing an Educational Video ${ }^{1}$
}

\author{
Ricky Telg and Peyton Beattie ${ }^{2}$
}

With the decrease in the price of video equipment, more educators are integrating video into courses and instructional programs. They are able to shoot video "in the field" and bring the "field" back to their presentations. They also can use video on websites or online video platforms such as YouTube or Vimeo. With its ability to combine sound and moving pictures, video is a powerful communication medium and is extremely effective for information delivery. As a result, video's use is widespread, ranging from television news to entertainment to education. Here are some ways you could integrate video into educational programs:

- Video clips in PowerPoint presentations

- Expert guests brought in by video

- Video clips on website or online video platforms to supplement an educational program

- Virtual tour of a laboratory or location not accessible by an entire class

However, a person who has never produced a video for an educational program needs to understand the video production process. The information presented in this fact sheet will assist you in developing an educational video production plan. For step-by-step information on how to shoot and edit your own video, please refer to companion fact sheet WC022/AEC340, Producing Your Own Video Program, available at https://edis.ifas.ufl.edu/publication/ WC022.

\section{Is video right for you?}

Before even planning the initial steps for a video program you need to decide if a video is right for the project. Because videos are such a prevalent part of our society, it has become quite easy to say, "Oh, let's just video this." So why use video?

- When the subject matter is eye-catching.

- When the visual material is interesting.

- Because people today are used to lots of visuals. They have grown up in the "multimedia generation." As a result, people hope visuals-such as video-are part of their educational experiences.

If you don't have a justifiable reason for producing an educational video program, though, then DON'T. Following are some issues to consider before beginning the video production process.

\section{Video is the medium to show motion.}

It is best to use video when motion is involved in the educational content you are trying to teach, for example, to demonstrate a skill. If your educational content doesn't lend itself to movement or motion, you may wish to use some other medium - print (handbooks, brochures, newsletters), photographs, or audio-that does not emphasize motion.

1. This document is AEC343, one of a series of the Department of Agricultural Education and Communication, UF/IFAS Extension. Original publication date February 1999. Revised May 2009 and June 2021. Visit the EDIS website at https://edis.ifas.ufl.edu for the currently supported version of this publication.

2. Ricky Telg, professor, Department of Agricultural Education and Communication; and Peyton Beattie, doctoral student, Department of Agricultural Education and Communication; UF/IFAS Extension, Gainesville, FL 32611.

The Institute of Food and Agricultural Sciences (IFAS) is an Equal Opportunity Institution authorized to provide research, educational information and other services

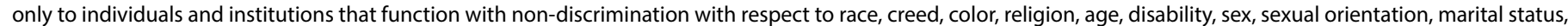

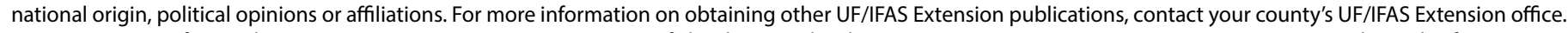
U.S. Department of Agriculture, UF/IFAS Extension Service, University of Florida, IFAS, Florida A \& M University Cooperative Extension Program, and Boards of County Commissioners Cooperating. Nick T. Place, dean for UF/IFAS Extension. 


\section{Consider "shelf-life."}

If you're producing an educational video, think about its "shelf-life." In other words, will the information still be relevant one or two years from now? If it will be out of date soon, then consider strongly if video is your best option. It may take a lot of time and effort to produce a quality video program. Will it be worth the effort to produce a video if the information is outdated before you get started?

\section{Consider how long it will take to produce the video.}

Video production can, indeed, be a lengthy process. It is not unusual for a program to take several months from the time it is initially conceptualized until the last video edit is made. So if you need a program in, say, three weeks, and you don't have a script and haven't thought about what shots you will need for a quality program, you may be out of luck. Simply put, video takes time.

\section{Instructional Considerations}

In addition to the question, "Is video right for me?" you also should consider the following questions as you develop your educational video:

- What is the need for the video program? Identifying a gap in the curriculum will help determine why the educational video is required.

- What are the goals and objectives of the video? Goals and objectives structure your plan of action. A goal is a general statement of what you hope the program will achieve. An objective is a measurable statement of what learners should be able to do (or do better) as a result of having watched the program.

- Who are the learners (the audience)? In any instructional environment, it's imperative to know as much about the learners - the intended audience-as possible. What are the audience members' ages, cultural backgrounds, interests, and educational levels? Knowing your learners and meeting the needs of your audience are the most important considerations in a video production.

- What will be the content? What information are you trying to say or get across to the audience members? What's the educational content? The answers to these questions should directly tie back to your goals and objectives.

- How will learners be assessed? How will you know your audience learned something? What questions would you want an audience member to be able to answer after having watched the video? Assessment is important, but many times is left out of the production process. Your objectives should be written in such a way that they can be measured. Thus, your objectives should guide how and what will be assessed.

- How will the video be evaluated? You may decide to test the video with a focus group of your intended audience. You may base your evaluation of success on the number of times a video is viewed, how long people watched the video, or the number of positive or negative reactions or comments the video received. Determining some type of evaluation criteria early on is essential. It would be helpful to determine the video analytics available from the online video platform you are using.

\section{Getting Started}

With the previous considerations in mind, let's say you have decided that a video program is the best medium to communicate with your audience. But where do you begin the production process and how much will the production cost? Here are some suggestions:

- Decide what level of quality you can afford. Will you plan it and shoot it on your own, and then have it professionally edited? Will you hire a production company to do it all? Will you do it all? Consider that the level of production you choose will affect the final product. For instance, using professional video cameras will allow you to make high-caliber video duplications. However, with the advent of low-cost computer editing equipment and digital video cameras, amateur video productions can be almost as good-on a shoestring budget-as some professional companies. How to plan and shoot your own video program is discussed in the fact sheet, Producing Your Own Video Program.

- Check out all area video production companies before deciding whom to hire. Ask a video production company for a copy of a recent video production to judge the quality of the work you would receive. Video production costs vary greatly from company to company, so shop around.

- Music and professional actors/narrators may add to the cost of your production. Using copyrighted music in your educational video production is illegal, unless you get approval from the music production company. For an educational production, the music company may let you use a song or music soundtrack for free, or the company may charge you a fee. Check with your video production company for details. You also may wish to investigate purchasing royalty-free music soundtracks that you can use over and over. A professional-sounding narrator or 
actor (if there is considerable on-camera narration) can add value to a project. Some narrators charge by the hour; others charge a flat fee for a project. Of course, cost will vary, depending on the length of the program. To save money in this area, consider hiring a local radio DJ or TV news anchor. Often, they will be willing to narrate nonprofit organizations' programs in exchange for personal and station credit at the end of your production.

\section{Scriptwriting}

Many video production companies will ask to see a script, a draft of a script, or at least an outline before they will estimate the cost of producing your video. To help you get started in the scriptwriting process, here are some tips:

- Start by dividing your page into two columns. Video commands, explanations of what shots you need, and other special effects should be listed on the left side; anything related to the audio should be included on the right side. This will help you and your producer visualize what you need to say, and will remind you to explain what you need to show. Table 1 presents an example of a two-column script.

Table 1. Example of two-column script.

\begin{tabular}{|l|l|}
\hline \multicolumn{1}{|c|}{ VIDEO } & \multicolumn{1}{c|}{ AUDIO } \\
\hline $\begin{array}{l}\text { Fade up to on-screen text: } \\
\text { "Starting a Successful Oil } \\
\text { Collection Program" }\end{array}$ & $\begin{array}{l}\text { Music fades up, then under } \\
\text { narration }\end{array}$ \\
\hline $\begin{array}{l}\text { Dissolve to shot of oil well } \\
\text { pumping. }\end{array}$ & $\begin{array}{l}\text { NARRATOR: } \\
\text { Oil. Black gold. Crude. Whatever } \\
\text { you want to call it, it's changed } \\
\text { our world. }\end{array}$ \\
\hline $\begin{array}{l}\text { Dissolve to shot underneath a } \\
\text { car, oil dripping into drain pan. }\end{array}$ & $\begin{array}{l}\text { With it, millions of people can } \\
\text { take to the roads or the skies for } \\
\text { easy, quick travel. }\end{array}$ \\
\hline $\begin{array}{l}\text { Cut to shot of traffic. } \\
\text { Cut to plane taking off. }\end{array}$
\end{tabular}

\section{- Decide what type of approach your video will need.} Will the program consist of narration only, covered by video? Will a professional actor be seen the entire time? Will you include interviews? While a straight-narrated script with no interviews is much easier to write and control, the use of interviews can make a much more interesting piece for your audience.

- Consider your audience. This is imperative throughout the entire production process. At the scriptwriting stage, such questions as the following arise: What will the audience members' interests be? How much do audience members know about this topic? What are your audience members' characteristics (age, socioeconomic status, education level, culture)?
- Consider the video's length. How long will you be able to retain your audience's attention? An adult audience's attention span will last about eight to ten minutes. For children, plan for three to five minutes. The video, of course, can be longer, especially if it is well produced or if the intended audience has a vested interest in the content presented. One of the most difficult aspects of writing a good script is including too much information, causing your video to be extremely lengthy. Remember you audience's attention span and consider breaking your lengthy video into shorter 5- to 8-minute segments.

- Write the way you speak. The key to writing a good script is to write the way you speak. Remember that unlike something written, your audience cannot go back and refer to something in a previous paragraph. Most people will not rewind a video to refresh their memories, so write in simple, easy-to understand sentences.

- Use on-screen text to support what you say. For instance, if your video is about an academic program with six components which you are about to describe one by one, show them on the screen as you tell the audience about them. This approach also will assist your visual learners with retain the information.

- Use music and special effects to avoid lengthy introductions and conclusions of topics within your video program. Also, by using music and special effects, you can indicate to your audience that you are changing topics.

- Keep it simple. Remember that your video tells a story without your needing to state everything. If your video shows children intent and focused on a classroom lesson, you do not need to tell your audience that children in this program are "intent and focused on their lessons."

\section{Applying Finishing Touches to the Script}

If you used two equal columns on 8.5 x 11 -inch paper, consider that a full, double-spaced column of narration (right side of the page) will last about 30-45 seconds per page. However, if you have interviews, that estimate can vary greatly, depending on the rate of speech of your subjects. Once you have your interview comments recorded and chosen, time them to the second for a more accurate total run-time estimate. Also, add another one to two minutes for music transitions between segments, a visual introduction with music, and credits.

After you've finished writing your script, let someone in your intended audience read it over. You may learn that you have included jargon or inadequate explanations in some 
areas, or you may have left gaps in the content. You also can determine what areas your intended audience will find the most and least interesting.

Before you have a narrator record the script, double-check the script to make sure it is exactly how you want it. This is an important step, because once your video is voiced by the narrator and then edited by the video production company, it can be very difficult (and very expensive) to change.

\section{Video Script Checklist}

When you've finished writing a polished draft of your script, use the following as a checklist to evaluate if you need to make any changes:

- Have I explained myself in simple language?

- When I read the script aloud, does it sound as if I'm talking to an audience (which is what I want), or just reading to an audience?

- Have I avoided technical language and jargon?

- Have I used music and natural sound (background sound) to help tell my story and break up constant narration or interviews?

- Do I have any lists or main ideas that could be reinforced as text on the video screen as they are being discussed?

- On the script, have I included proper titles and name identification of on-screen speakers?

- In the video column of the script, have I described the type of video shots I need?

- Have I described special graphics or other effects in the video column?

\section{Shooting}

The shooting stage is what most people consider the production phase of a video program. It's the glamour stage, the "lights, camera, action" stage. However, as you have already read, much planning goes into the program before any video is ever shot. If you have hired a production company, you may be asked to accompany photographers as they shoot video to make sure they get everything the way you want it. If you're going to shoot the video yourself, refer to the fact sheet Producing Your Own Video Program for some helpful tips on selecting video equipment, shooting video effectively, and using video editing software.

\section{Editing}

Editing a video is a creative process. It's where you put all the various parts together into one, coherent, comprehensive program. It's also time-consuming. The industry rule of thumb is that for one minute of finished video in a program, it takes at least one hour of editing time. So for a 10-minute program, expect a minimum of 10 hours of editing time to complete it. Depending on the number of special effects you want to include, that amount of time may double. Again, refer to the fact sheet, Producing Your Own Video Program for some help.

\section{Checklist for Planning an Educational Video Program}

- Make sure video is right for your purpose.

- Think "final outcome." What do you want your audience to know or do after viewing the video?

- Script (or at least outline) the video shoot. Know what will be said and shown.

- Then shoot the video. Most people skip right to the shooting step before doing any planning. 